\title{
MYCORRHIZAL INOCULATION OF ONION (ALLIUM CEPA L.) IN THE EARLY DEVELOPEMENT STAGES
}

\author{
Katalin Fekete ${ }^{1}$, Renáta Honfi ${ }^{2}$, Zoltán PaP ${ }^{1}$ \\ ${ }^{1}$ Szent István University, Faculty of Horticulture, Department of Vegetable and \\ Mushroom growing, 44 Ménesi Street, 1118 Budapest, Hungary \\ ${ }^{2}$ Szent István University, Faculty of Horticulture, BSc student of Horticultural Science \\ fekete.katalin@kertk.szie.hu
}

\begin{abstract}
The onion (Allium cepa) is one of the most widely cultivated vegetables. As a food item, it is usually served cooked, as a vegetable or part of a prepared savoury dish, but can also be eaten raw or used to make pickles or chutneys.

Mycorrhiza fungi are special fungi, which live in connection with plant roots. These are symbiotic fungi which have three main types: arbuscular mycorrhiza (AM), ectomycorrhiza and ectendomycorrhiza. AM are probably the most widespread plant symbionts and are formed by $80-90 \%$ of land plant species. Crops inoculated with AM have higher yield and quality, and those plants react to stress factors better (e.g. drought, high temperature). Several Allium spp. responded with growth promotion on AM inoculation. According to studies AM fungi also has a positive effect on nutrient content.

The aim of our experiment was to find an appropriate method for inoculation of onion seedlings, and define the minimum time for the appearance of symbiosis under greenhouse conditions.

The experiment took place at Szent István University Faculty of Horticultural Science, at the experimental glasshouse of the Department of Vegetable and Mushroom growing, from 11th September 2017. We used Daytona F1 onion seeds, the media was Latagro KB2 type peat and two types of mycorrhizal products: MycoGrow and Aegis Irriga. The experiment was made with 12 treatments with 30-30 seeds per each treatment. During the experiment, chemically treated and non-treated seeds were used. The seedlings were sampled 5, 7 and 14 weeks after sowing, 5-5 seedlings from each treatment per time. Altogether 96 painted and prepared samples were checked, each with 3-3 roots with a Zeiss Axio Imager A2 microscope.

The results showed the appearance of mycorrhizal fungi in a few treatments. In our examination not only typical AM fungi were found, but also in a treatment we found hyphaes with big amount of septas.

The results show opportunity of artificially infecting transplants after a few weeks with mycorrhizal products. However, continuing the experiment is necessary with some modification of the factors, to make the procedure more effective.
\end{abstract}

Keywords: arbuscular mycorrhiza, onion, seedling, inoculation, colonization

\section{INTRODUCTION}

The onion (Allium cepa L.) is one of the most widely cultivated vegetables. Its close relatives are the garlic, shallot, leek, chive, which all belong to the Alliaceae family. Onions are cultivated and used around the world. As a food item, these are usually served cooked, as a vegetable or part of a prepared savoury dish, but can also be eaten raw or used to make pickles or chutneys (WEB1).

According to FAOSTAT (2018), worldwide, in the last 10 years there were ups and downs both in the harvested area and yields, but due to it, in the last 6 years it seems to stabilize. In Hungary, onion is also one of the most widely cultivated and used vegetable. In 2016, the harvested area was around 2000 ha-s, the yield was $32 \mathrm{t} \mathrm{ha}^{-1}$, but with intensive technology some growers could reach $60-70 \mathrm{t} \mathrm{ha}^{-1}$ yield (LEDÓ ET AL., 2017)

Mycorrhiza fungi are special fungi, which live in connection with plants roots. These are symbiotic fungi which have three main types: arbuscular mycorrhiza, ectomycorrhiza and ectendomycorrhiza. Arbuscular mycorrhiza (AM) has aseptated hyphae, colonizes the roots intracellular, most arbuscular mycorrhizal fungi belong to the Glomero taxa. 
Ectomycorrhiza has septated hyphae, colonizes the roots extracellular, most ectomycorrhiza fungi belong to the Basidio or Asco taxa. Ectendomycorrhiza has septated hyphae, colonises the root intracellular and the most ectendomycorrhiza fungi belong to the Basidio or Asco taxa (SMITH AND READ, 2008).

AM are probably the most widespread plant symbionts and are formed by $80-90 \%$ of land plant species. This includes numerous important horticultural crops among the Solanaceae (e.g. tomato, eggplant or petunia), the Alliaceae (e.g. onion, garlic and leek), fruit trees (e.g. grapevine, citrus spp.), ornamentals and herbal plants (e.g. basil, thyme, rosemary) (ROUPHAEL ET AL., 2015).

Crops inoculated with AM have higher yield and quality, and those plants react to stress factors better (e.g. drought, high temperature). Several Allium spp. responded with growth promotion on AM inoculation. Onion (Allium cepa) plants inoculated with AM, grown in pots with mineral soil had a higher biomass than non-inoculated plants and reached marketable size ( $>25 \mathrm{~mm}$ bulb diameter) 2-3 weeks earlier. This AM inoculation caused furthermore firmer bulb formation of onions. Mycorrhizal inoculation led to $22 \%$ increased yields of onions compared to non-inoculated controls (BAUM ET AL., 2015).

Inoculating horticultural crops with $\mathrm{AM}$ is becoming common practice, especially in intensive horticultural cropping systems. However, a high-quality inoculum is necessary for successful root colonization with AM (ROUPHAEL ET AL., 2015). According to HART AND FORSYTHE (2012), AM fungi also have a positive effect on nutrient content.

The aim of our experiment was to find an appropriate method for inoculation of onion seedlings, from treated and non-treated seeds and define the minimum time for the appearance of symbiosis under greenhouse conditions.

\section{MATERIAL AND METHOD}

The experiment took place at Szent István University Faculty of Horticultural Science, at the experimental glasshouse of the Department of Vegetable and Mushroom growing, 11th September 2017. We used Daytona F1 onion seeds, the medium was Latagro KB2 type peat. Two types of mykorrhizal products were used: MycoGrow and Aegis Irriga. The technical information of MycoGrow said that it could be given for the plant both irrigated and mixed in the media, while Aegis Irriga is just given with irrigation.

The experiment was made with 12 treatments with 30-30 seeds per each treatment. During the trial chemically treated and non-treated seeds were used. The Table 1 shows the code of the treatments: if the seed is chemically treated or not, the method of the treatment (colonization) and the name of the product and the quantity.

The quantity of the products was calculated from the Technical information. In the case of

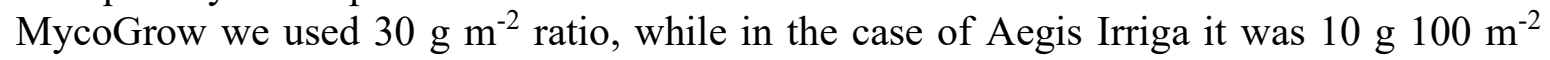
ratio. Amounts of the mycorrhizal products for one tray were calculated from these ratios.

During the experiment, fertilizer and plant protection were not used. Seedlings were irrigated and supplementary lightings were used, when it was needed.

Temperature and humidity were measured during the experiment with a Voltcraft DL181THP device. The maximum temperature was $28.85{ }^{\circ} \mathrm{C}$, the minimum was $14.33{ }^{\circ} \mathrm{C}$. The maximum humidity was $90.28 \%$, the minimum was $59.94 \%$ during the experimental time. During the experimental time, the climate suited for the onion seedlings. 
Review on Agriculture and Rural Development 2018 vol. 7 (1-2) ISSN 2063-4803

Table 1. Treatments used during the experiment

\begin{tabular}{|c|c|c|c|}
\hline Treatment Code & $\begin{array}{c}\text { Chemically treated } \\
+/-\end{array}$ & $\begin{array}{c}\text { Method of the } \\
\text { treatment }\end{array}$ & $\begin{array}{c}\text { Product name, } \\
\text { quantity }\end{array}$ \\
\hline A & + & mixed in the media & MycoGrow, $5.2 \mathrm{~g}$ \\
\hline B & - & mixed in the media & MycoGrow $5.2 \mathrm{~g}$ \\
\hline C & + & mixed in the media & MycoGrow $10.4 \mathrm{~g}$ \\
\hline D & - & mixed in the media & MycoGrow $10.4 \mathrm{~g}$ \\
\hline E & - & with irrigation & Aegis Irriga $0.017 \mathrm{~g}$ \\
\hline F & + & with irrigation & Aegis Irriga $0.017 \mathrm{~g}$ \\
\hline G & - & with irrigation & MycoGrow $5.2 \mathrm{~g}$ \\
\hline H & + & with irrigation & MycoGrow $5.2 \mathrm{~g}$ \\
\hline I & - & with irrigation & Two product mixed \\
\hline J & + & with irrigation & Two product mixed \\
\hline Control + & - & - & no treatment \\
\hline Control - & & & no treatment \\
\hline
\end{tabular}

The seedlings were sampled 5, 7 and 14 weeks after sowing, 5-5 seedlings from each treatment per time. The first sampling was at 16th October 2017. The second sampling time was at 30th October 2017. The third sampling time was at 18th December 2017. Roots were washed and put in Falcon tubes, filled with $60 \%$ alcohol until further measurements.

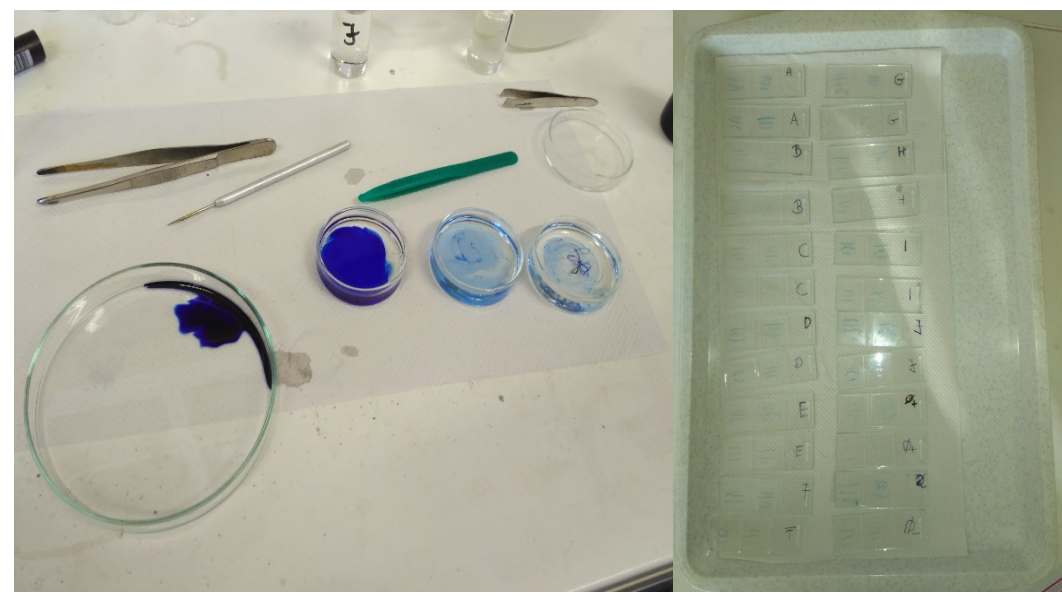

Figure 1. The method of painting; Dissections

To make mycorrhizal fungi visible, a special painting method was used. First, roots were cleaned from the remaining soil parts and from the alcohol with distilled water. Then roots were put in $10 \%(\mathrm{w} / \mathrm{v})$ potassium-hidroxide and cooked in $60{ }^{\circ} \mathrm{C}$ for 60 minutes. Then potassium-hidroxide was washed away with distilled water and roots were put in lacticacid for a night. The next day the roots were painted with aniline-blue. The roots were put in a bigger Petri-plate, paint was dropped on the roots and after a few seconds the 
remaining paint was washed away (Figure 1). Then the roots were put in lactic-acid for a night, to properly wash away the unnecessary paint. This painting method can vary a little due to the roots thickness.

After painting, dissections were made from the roots. Aproximately, 1-1,5 cm long pieces from the roots were cut and put in a few drops of lactic-acid on a slide. Three roots were put under each coverslip (Figure 1). Altogether 96 painted and prepared samples were checked, each with 3-3 roots with a Zeiss Axio Imager A2 microscope.

\section{RESULTS}

The result of the mycorrhizal colonization could be seen in the microscopic pictures. In treatment „C", which was chemically treated, and mixed double dose of MycoGrow in the peat, a long hyphae can be seen. In the hyphae there are no septas (Figure 2). These hyphae are long enough, to say, at this treatment the colonization was successful.

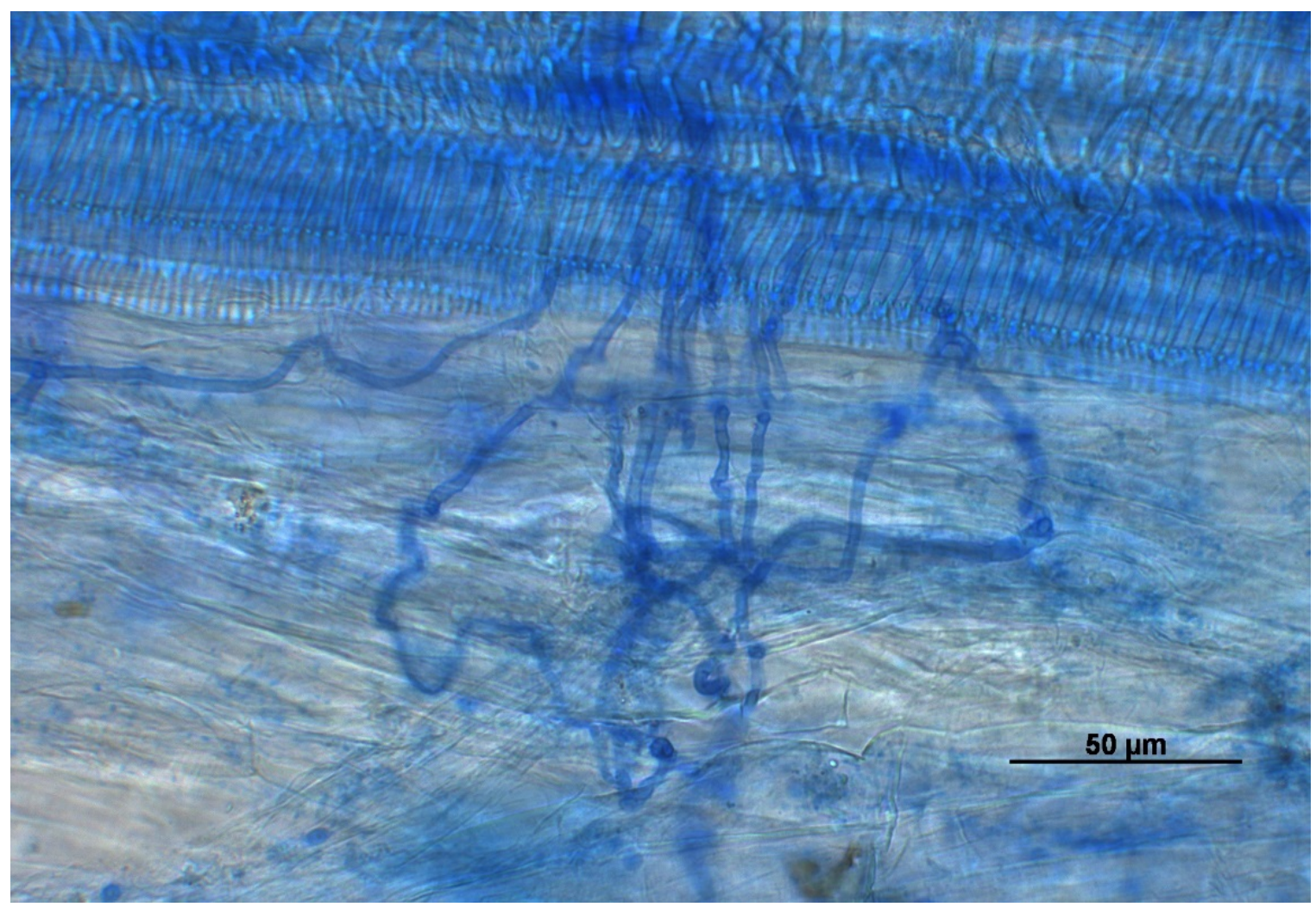

Figure 2. Treatment „,C", 2. sampling

There are also mycorrhizal hyphae on Figure 3 which was taken from Treatment „C" from the second sampling time. In this picture, septas in the hyphae could be seen (arrows), so this was not that type of mycorrhiza fungi we looked for, but its spore could be in the mycorrhizal product beside the other type of mycorrhiza fungi.

In other cases, we did not find any inoculated root from 96 examined roots. Also, there were no remarkable difference between treated and non-treated seeds. However, it is intersting to find an inoculated root in a treatment in which chemically treated seeds were used. 


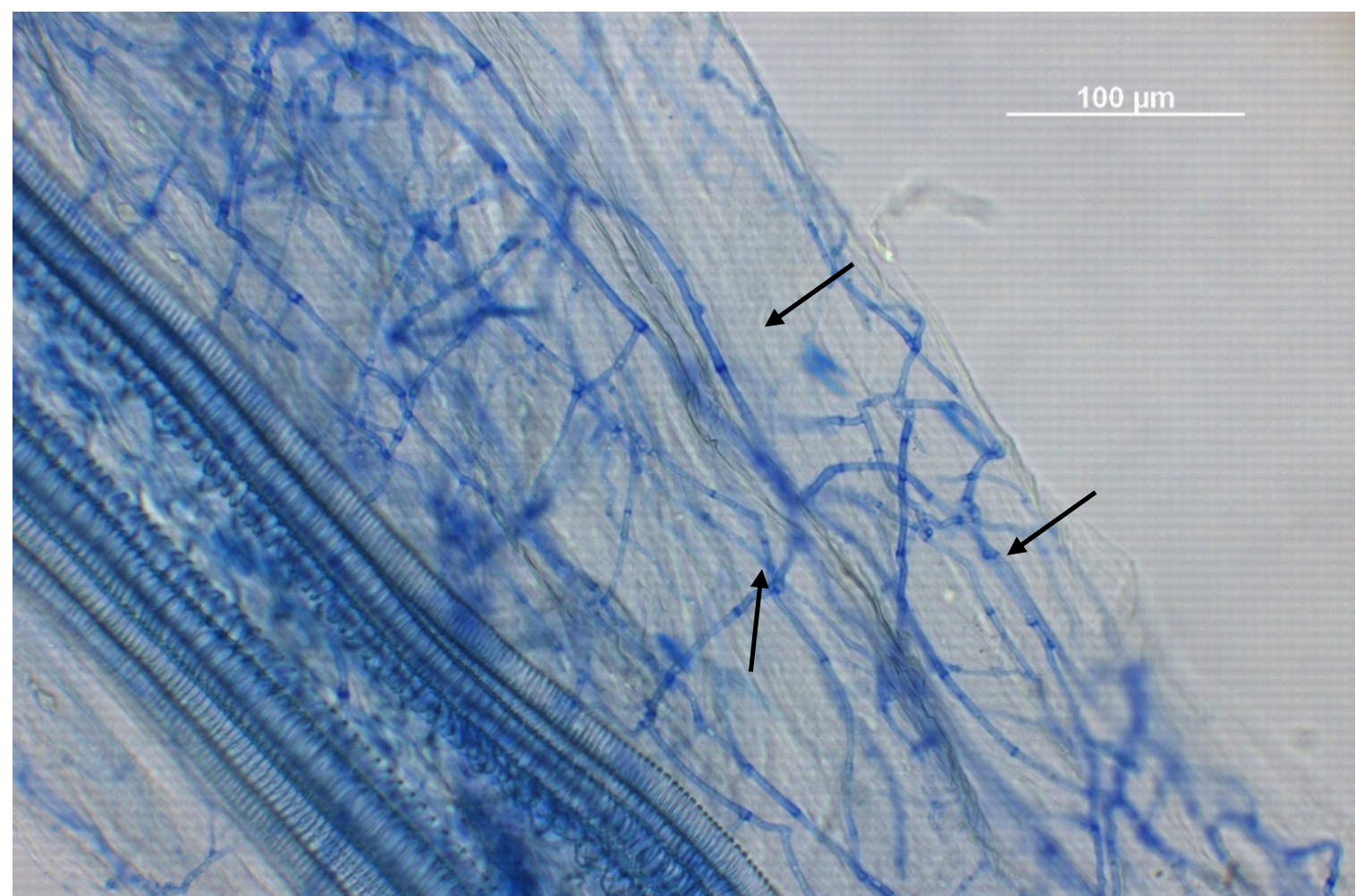

Figure 3. Treatment „C”, 2. sampling

\section{CONCLUSIONS}

The results showed the appearance of mycorrhizal fungi in a few treatments after 7 weeks from sowing. In our examination not only typical AM fungi were found, but also in a treatment we found hyphae with big amount of septas. Symbiont activity could not be high in our experiment, however in other studies a higher value of colonization was recorded. For example, TAWARAYA ET AL. (2012) had a $94 \pm 3 \%(n=4)$ colonization on Allium fistulosum 58 days (approx. 8 weeks) after sowing. The experiment took place in Japan. There the medium was andosol, the fungal inoculum consisted not only spores, like in our experiment, but also extraradical hyphae and infected roots with Glomus R-10. Amount of the inoculum was $75 \mathrm{~g} \mathrm{~kg}^{-1}$.

Results show opportunity of artificially infecting transplants after a few weeks with mycorrhizal products. However, continuing the experiment is necessary with some modification of some factors (like type of substrate, or used inoculation method), to make the procedure more effective.

\section{REFERENCES}

BAum, C., El-Tohamy, W., Gruda, N. (2015): Increasing the productivity and product quality of vegetable crops using arbuscular mycorrhizal fungi: A review. Scientia Horticulturae 187: 131-141.

FAOSTAT: http://www.fao.org/faostat/en/\#data/QC/visualize 2018.03.18.

LedÓ, F., APÁti, F., DOMJÁN, E., Gubacsi, Z. (2017): FruitVeb - Annual fruit and vegetable report 2017. 
HART, M.M., ForSYTHE, J.A. (2012): Using arbuscular mycorrhizal fungi to improve the nutrient quality of crops; nutritional benefits in addition to phosphorus. Scientia Horticulturae 148: 206-214.

Rouphael, Y., Franken, P., Schneider, C., Schwarz, D., Giovannetti, M., Agnolucci, M., De Pascale, S., Bonini, P., Colla, G. (2015): Arbuscular mycorrhizal fungi act as biostimulans in horticultural crops. Scientia Horticulturae 196: 91-108.

Smith, S.E., READ, D.J. (2008): Mycorrhizal symbiosis. Third Edition. Academic Press, New York. 188 p.

TAWARAyA, K., Hirose, R., Wagatsuma, T. (2012): Inoculation of arbuscular mycorrhizal fungi can substantially reduce phosphate fertilizer application to Allium fistulosum L. and achieve marketable yield under field condition. Biology and Fertility of Soils 48(7): 839-843.

WEB1: https://en.wikipedia.org/wiki/Onion 